\title{
STUDY ON PREPARATION OF RICE-WHEAT BREAD USING PREMIX
}

\author{
P. Mahalingam ${ }^{1}$, S. Veluppillai ${ }^{1}$ and S. Ekanayake ${ }^{2}$
}

\begin{abstract}
In this study the formulation of rice-wheat bread premixes stored for 3, 4, 6 and 8 weeks were investigated aiming to find out the feasibility of preparing rice-wheat bread using premix (rice flour, wheat flour, yeast and bread improver). The breads produced with premixes (rice-wheat premix bread; $R W P B)$ were compared with wheat bread (WB) and rice-wheat bread (RWB) taking into account physical, nutritional and sensorial parameters. Breads were prepared using a basic formula by straight dough method. Based on the determination of gluten percentage of different combinations of rice-wheat flour mixes, flour mix with $20 \%$ rice and $80 \%$ wheat was selected to prepare premixes. There were no significant differences ( $p>0-05)$ between the physical, nutritional and sensorial qualities of $R W B$ and $R W P B$ while the qualities of $R W B$ and $R W P B$ differed significantly $(p<0.05)$ from the qualities of $W B$. Moisture content of $R W B$ and $R W P M$ was significantly higher $(p<0.05)$ than that of $W B$. The total sugar contents of $R W B$ and $R W P M$ were significantly higher $(p<0.05)$ than that of $W B$ while total protein content of RWB and RWPM was significantly lower $(p<0.05)$ than that of WB. Fat content of WB was significantly lower than that of $R W B$ and $R W P M$. There were no significant differences $(p>0.05)$ in ash and crude fiber content of all types of breads. The specific gravity of WB was higher than that of RWB and RWPM and there were no significant differences in the sensory qualities except crumb colour and crust colour. Even though RWB and RWPM differed in some qualities with $W B$, they did not differ in qualities among them. Therefore from this study it can be concluded that rice - wheat breads can be prepared using premixes stored up to 8 weeks with the qualities consistent with that of bread prepared using fresh rice-wheat flour mix.
\end{abstract}

Key words: premix, wheat bread, rice-wheat bread, rice-wheat premix bread

\section{INTRODUCTION}

Bread is one of the most versatile and convenience food. It plays a major role as breakfast food among Sri Lankans. Nowadays the evolution of baking methods has substantially shortened the processing time in bread making, which is approximately 2.5 hours for the bread making (Valduga et al., 2004). Use of premixes in baking industries is widely practiced worldwide and it saves the time in production process. Further, it is advantageous for the reduction of costs, product standardization and quality, labour optimization, simplicity in sanitization and lowering physical room for raw material storage (Valduga et al., 2004). The use of premixes in bread making in Sri Lanka will be most promising since bread plays a crucial role as breakfast food for most Sri Lankans and it is produced by the bakeries in large scale.

The main ingredient for bread is wheat flour. Sri Lanka is totally dependent on the imported wheat since the wheat is not grown in Sri Lanka. Nowadays due to the continuous hikes 
in wheat price in the world market, Sri Lanka is in a position to find any other locally available raw material to be used as a substitute for wheat flour for the baking industry.

Rice, the staple food of Sri Lankans, is widely grown in Sri Lanka as the soil and climatic conditions are suitable for paddy cultivation. Therefore it is highly desirable to partially substitute rice flour for wheat flour in the preparation of bread and other bakery products. It would help lessen the total dependence on imported wheat flour. Thus in this study rice flour was used to substitute a particular percentage of wheat flour in the preparation of bread. Several researchers found out that it is possible to prepare breads with acceptable qualities by partial substitution of wheat flour with rice flour (Veluppillai et al., 2010, Kadan et al., 2001, Nishita and Bean, 1979 and Noomhorm and Bandola, 1994).

Therefore in the present study it was decided to investigate the feasibility of preparing ricewheat bread using premix. The objectives of this study were to evaluate the feasibility of preparing rice-wheat premix bread with qualities consistent with rice-wheat bread and to analyze the keeping time of premix with no reduction of bread quality.

\section{MATERIALS AND METHODS}

All the experiments were performed in triplicates.

\section{Materials}

The reagents used were of analytical grade and purchased from standard sources (Sigma Chemical Company, USA; BDH Ltd).The ingredients used for bread making were wheat flour, white rice flour, yeast (Mauripan), table salt, sugar, margarine, bread improver (AB Mauri Lanka) and water. All ingredients were purchased from local market except for white rice flour purchased from rice processing unit, Kundasala.

\section{Estimation of gluten percentage in premix}

Gluten percentage was estimated for different mixtures of wheat flour and rice flour (wheat flour: rice flour ratios were 1:0, 9:1, 8:2, 7:3, $6: 4)$. Weighed sample of wheat flour and rice flour was mixed thoroughly and made into dough by kneading. The dough was held under running tap water to obtain the gluten and the dry weight of the gluten was obtained using oven drying. Gluten percentage was calculated.

\section{Preparation of bread premix}

The ingredients wheat flour $(800 \mathrm{~g})$, rice flour $(200 \mathrm{~g})$, yeast $(7 \mathrm{~g})$ and bread improver $(2 \mathrm{~g})$ were mixed thoroughly. The premix prepared was packed in to $1 \mathrm{~kg}$ packets using polythene in four separate sets (each set contained 4 packets) and stored for 3, 4, 6 and 8 weeks under normal room condition.

\section{Microbial analysis of premixes}

Microbial analysis of the premixes stored for 4 and 8 weeks were performed using standard plate count technique. The premix sample (1g, stored for 4 weeks) was weighed aseptically in to a sterile container. The sample was homogenized with $9 \mathrm{~mL}$ of sterile water $\left(10^{-1}\right.$ dilution) and serial dilutions were prepared up to $10^{-4}$ dilution. Sample $(1 \mathrm{~mL})$ was plated out from each dilution on solidified agar medium in triplicates. The number of colonies were counted using colony counter and the number of colony forming units (CFU) were calculated as follows.

$\mathrm{CFU} / \mathrm{g}=$ Number of colony counted $\mathrm{x}$ Reciprocal of dilution $\mathrm{x}$ Reciprocal of dilution volume plated

This procedure was repeated for the premix stored for 8 weeks.

\section{Bread making}

WB [wheat flour $(1000 \mathrm{~g})$, yeast $(7 \mathrm{~g})$, sugar $(20 \mathrm{~g})$, salt $(15 \mathrm{~g})$, margarine $(40 \mathrm{~g})$, bread 
improver (2g) and water (600g)], RWB [ingredients same as for WB except wheat flour (800g) and rice flour (200g)] and RWPB (ingredients same as for WB except premix) were prepared by straight dough method. The dough were baked in an electrical oven at $235^{\circ} \mathrm{C}$ for 35 mins.

\section{Analysis of breads}

The moisture, total sugar, total protein, fat, fiber and ash contents of the breads were analysed by standard methods (Pearson, 1976).Width, height and length of the breads were measured. Breads were submitted for sensory analysis in order to evaluate mouth feel, crumb texture, crumb color, crust color and overall acceptance. The bread samples were homogenously sliced and served with water in identical containers for twenty untrained panel members selected from students and staff of the Food Research Unit, Gannoruwa to perform the evaluation using a hedonic scale of 5 points. The scores assigned were like extremely -5 , like moderately -4 , like slightly -3 , neither like nor dislike -2 and dislike slightly -1 .

The breads prepared from the premixes stored for $3,4,6$ and 8 weeks were compared with
RWB and WB separately for their proximate, morphological and sensorial qualities.

\section{Statistical Analysis}

Statistical analysis was performed using Minitab program (Version 13) and SAS program (Version 8) to compare the results. The level of significance was considered at $\mathrm{p}<0.05$.

\section{RESULTS AND DISCUSSION}

Gluten percentage of different mixtures of wheat flour and rice flour

Gluten percentage of different combinations of wheat flour and white rice flour are shown in Figure 01 . The amount of gluten was reduced with increasing percentage of substitution with rice flour because the rice flour does not have gluten (Sivaramakrishnan et al., 2004). There was no significant difference between the gluten percentage of flour mixes that contained $10 \%$ and $20 \%$ of rice flour. Therefore flour containing $20 \%$ rice flour and $80 \%$ wheat flour was selected to prepare premix breads.

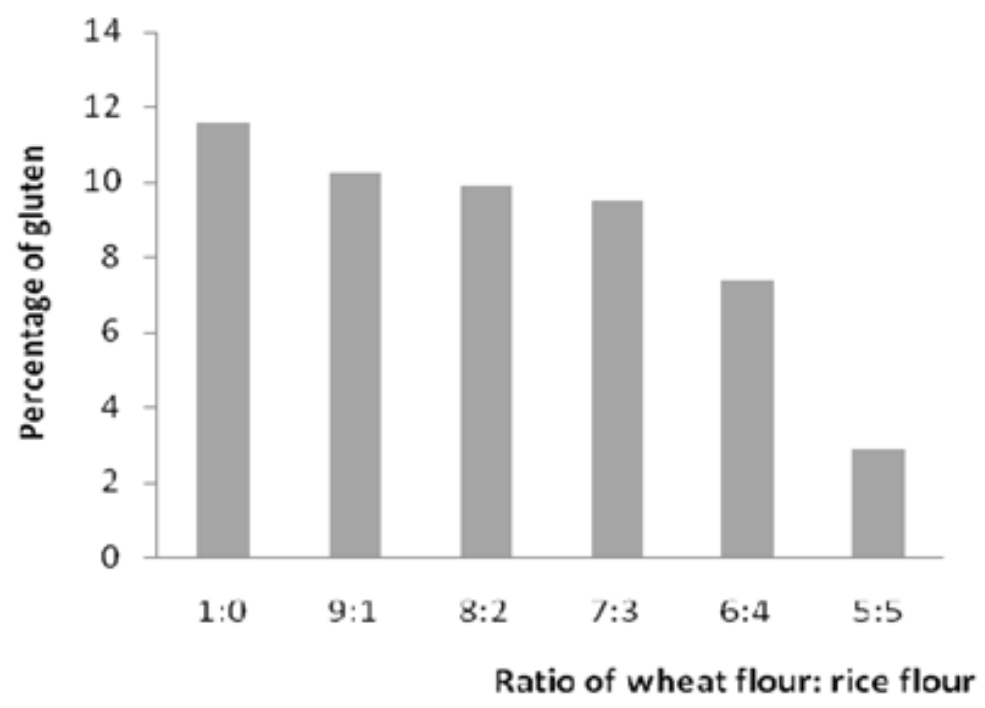

Figure 01: The mean gluten percentage of six different flour combinations of wheat flour and rice flour. 


\section{Microbial quality of premixes}

Counting of colonies was not possible for 10 ${ }^{1}$ and $10^{-2}$ dilutions from both 4 weeks and 8 weeks samples due to high density of the colonies. However colony counting was possible for the $10^{-3}$ and $10^{-4}$ dilutions for both samples. Colony count for the 4 weeks premix was $3.5 \times 10^{4} \mathrm{CFU} / \mathrm{g}$, and for the 8 weeks premix it was $4.5 \times 10^{4} \mathrm{CFU} / \mathrm{g}$. The colony count increased with the storage period.

\section{Comparison of wheat bread, rice-wheat} bread and rice-wheat premix bread

The proximate composition of the breads is shown in Table 01. Moisture content RWB and RWPB did not differ among them but their moisture contents were significantly higher than that of WB.

Total sugar content of WB was significantly $(\mathrm{p}<0.05)$ low compared with RWB and RWPB while the RWB and RWPB did not significantly $(p>0.05)$ differ among them. Lower total sugar content of WB than other breads could be attributed to the fact that wheat contains less amount of carbohydrate $(61.6 \%)$ than rice $(71.1 \%)$ (Juliano, 1985).

Protein content in the WB $(11.3 \%)$ was significantly higher $(\mathrm{p}<0.05)$ than the other products. This is due to the higher protein content $(10.6 \%)$ of wheat than white rice (7.3\%) (Juliano, 1985). Protein content did not significantly differ $(p>0.05)$ among the RWB and RWPB. However with increased keeping time of the premix, protein content of the premix breads showed a decline. This decline in protein content could be attributed to the moisture content of the RWPB. Higher proteolytic activities during the storage are related to the higher moisture level in the flour (Nasir et al., 2003). Therefore in the premixes some proteins may be hydrolysed due to proteolytic activities during storage.

Fat content of WB was lower than that of RWB and RWPB. It is because of lower fat content of wheat than that of rice (Juliano, 1985). Ash and crude fiber contents of the all types of breads were not significantly $(p>0.05)$ different.

Table 01: Proximate composition of different types of breads

\begin{tabular}{|c|c|c|c|c|c|}
\hline Type of bread & $\begin{array}{c}\text { Moisture } \\
(\%)\end{array}$ & $\begin{array}{c}\text { Total sugar } \\
(\%)\end{array}$ & $\begin{array}{c}\text { Total protein } \\
(\%)\end{array}$ & Fat (\%) & $\begin{array}{c}\text { Crude fiber } \\
(\%)\end{array}$ \\
\hline \multirow{2}{*}{ Wheat bread } & 39.61 & 47.59 & 10.78 & 2.59 & 2.25 \\
\hline & $( \pm 0.09)$ & $( \pm 0.36)$ & $( \pm 0.06)$ & $( \pm 0.03)$ & $( \pm 0.04)$ \\
\hline \multirow{2}{*}{ Rice-wheat bread } & 40.95 & 49.99 & 8.91 & 2.72 & 2.25 \\
\hline & $( \pm 0.06)$ & $( \pm 0.26)$ & $( \pm 0.15)$ & $( \pm 0.03)$ & $( \pm 0.03)$ \\
\hline \multirow{2}{*}{$\begin{array}{l}\text { Rice-wheat premix bread made } \\
\text { from premix stored for } 3 \text { weeks }\end{array}$} & 40.89 & 49.00 & 8.61 & 2.71 & 2.25 \\
\hline & $( \pm 0.05)$ & $( \pm 0.05)$ & $( \pm 0.05)$ & $( \pm 0.02)$ & $( \pm 0.03)$ \\
\hline \multirow{2}{*}{$\begin{array}{l}\text { Rice-wheat premix bread made } \\
\text { from premix stored for } 4 \text { weeks }\end{array}$} & 40.92 & 49.94 & 8.49 & 2.71 & 2.25 \\
\hline & $( \pm 0.10)$ & $( \pm 0.06)$ & $( \pm 0.04)$ & $( \pm 0.01)$ & $( \pm 0.01)$ \\
\hline \multirow{2}{*}{$\begin{array}{l}\text { Rice-wheat premix bread made } \\
\text { from premix stored for } 6 \text { weeks }\end{array}$} & 40.88 & 49.89 & 8.30 & 2.71 & 2.25 \\
\hline & $( \pm 0.03)$ & $( \pm 0.02)$ & $( \pm 0.09)$ & $( \pm 0.01)$ & $( \pm 0.01)$ \\
\hline \multirow{2}{*}{$\begin{array}{l}\text { Rice-wheat premix bread made } \\
\text { from premix stored for } 8 \text { weeks }\end{array}$} & 40.87 & 49.69 & 8.08 & 2.70 & 2.25 \\
\hline & $( \pm 0.06)$ & $( \pm 0.03)$ & $( \pm 0.07)$ & $( \pm 0.01)$ & $( \pm 0.03)$ \\
\hline
\end{tabular}


Width, length and height of the WB was higher than the others (all breads were prepared using same weight dough) while the RWB and RWPB did not significantly $(p>0.05)$ differ among them. The higher width length and height of WB than other breads indicates that the WB has higher specific volume than other breads. Among the cereals, wheat and rye contain the protein called 'gluten', which makes them superior to other cereals for the production of porous baked goods. The gluten is the component of dough that determines the ability to retain gas (carbondioxide) generated during fermentation in the form of numerous gas cells and proper balance of viscous flow and elastic strength so that the loaf can expand adequately during proofing and the early stages of baking (Stauffer, 1998). Therefore, when substituting wheat flour with rice flour, the amount of gluten will be reduced and there will be a lack of gluten net work to capture the carbon dioxide formed during fermentation.

Results for the sensory evaluation are shown in Figure 02. Mean scores obtained for mouth feel, crumb texture and overall acceptability for all types of breads did not differ significantly $(p>0.05)$ while the mean scores for crumb color and crust colour of the WB were significantly higher $(p<0.05)$ than that of other breads. The sensory properties of RWB and RWPB did not differ significantly $(\mathrm{p}>0.05)$ among them. Thus it can be concluded that the WB, RWB and RWPB had almost similar consumer acceptability.

\section{CONCLUSION}

The study revealed that the bread premix (wheat flour, rice flour, yeast and bread improver) was consistent in quality in bread making in terms of nutrition and sensory characters over a period of two months; that is, the RWB can be prepared using premix stored up to 2 months with the qualities equal to that of RWB made from fresh flours.

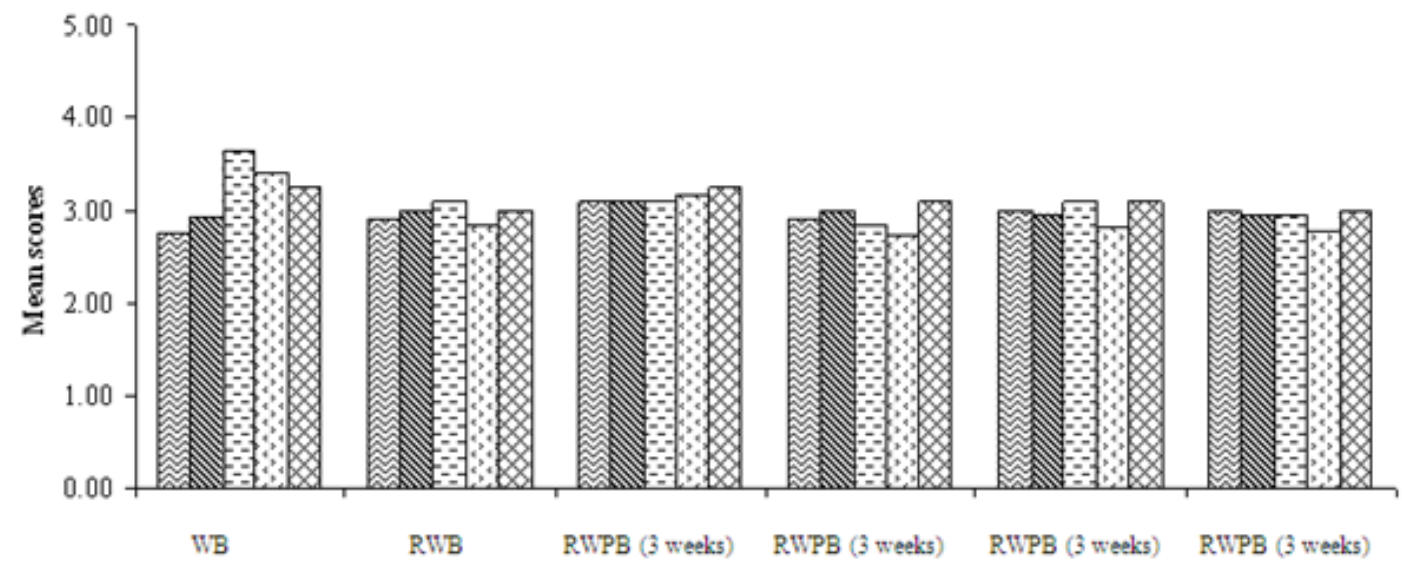

Figure 02 Mean scores obtained for mouth feel; (因), crumb texture; $;$, crumb colour;(廌), crust colour; (H.]) and overall acceptability; ( 18 ) of different types of bread.

(WB- wheat bread, RWB- rice-wheat bread, RWPB-rice-wheat premix bread) 


\section{REFERENCES}

Juliano, B. O. (1985). Rice chemistry and technology. $2^{\text {nd }}$ edition. St. Paul, MN: American Association of Cereal Chemists, Inc. 774pp.

Kadan, R. S., Robinson, M. G., Thibodeaux, D. P. and Pepperman, A. B. (2001). Texture and other physicochemical properties of whole rice bread. Journal of food science. 66(7): 940-944. http://dx.doi.org/10.1111/j.1365-2621.2001.tb08216.x

Nasir, M., Butt, M., Anjum, F. M., Sharif, K. and Minhas, R. (2003). Effect of moisture on shelf life of wheat flour. International Journal of Agriculture and Biology. 5(4): 458-459.

Nishita, K. D. and Bean, M. M. (1979). Physiochemical properties of rice in relation to rice bread. Cereal Chemistry. 56(3): 183-189.

Noomhorm, A. and Bandola, D. C. (1994). Effect of rice variety, rice flour concentration and enzyme levels on composite bread quality. Journal of the Science of Food and Agriculture. 64(4): 433-440. http://dx.doi.org/10.1002/jsfa.2740640407

Pearson, D. (Ed.) (1976). The chemical analysis of foods. $7^{\text {th }}$ edition. Churchill, Livingstone, Edinburgh, London. 575pp.

Sivaramakrishnan, H. P., Senge, B. and Chattopadhyay, P. K. (2004). Rheological properties of rice dough for making rice bread. Journal of Food Engineering. 62: 37-45.

Stauffer, C.E. (1998). Principles of dough formation, In: Cauvain, S.P. and Young, L.S. (Eds.). Technology of Breadmaking, Blackie Academic and Professional, London, UK. 262295. http://dx.doi.org/10.1016/S0260-8774(03)00169-9

Valduga, E., Sfredo, M. A. and Di Luccio, M. (2004). Assessment of flow and technological behaviour of french bread premixes. Brazilian Journal of Food and Nutrition. 15(1): 1-6.

Veluppillai, S., Nithyanantharajah, K., Vasantharuba, S., Balakumar, S. and Arasaratnam, V. (2010). Optimization of bread preparation from wheat flour and malted rice flour. Rice science. 17(1): 51-59. . http://dx.doi.org/10.1016/S1672-6308(08)60104-3 